\title{
Estimating the Optimal Model for Traffic Accidents in Jordan for the Period of (1995-2010)
}

\author{
Adeeb A. Alrahamneh ${ }^{1} \&$ Reda M. AlBtoush ${ }^{2}$ \\ ${ }^{1}$ Assosiate Professor, Applied Statistics, Faculty of Business, Al-Balqa Applied University, Jordan \\ ${ }^{2}$ Assistant Professor, Management, Faculty of Business, The University of Jordan, Jordan \\ Correspondence: Adeeb Ahmad Ali Alrahamneh, Applied Statistics, Faculty of Business/Al-Balqa Applied \\ University, Jordan. Tel: 962-772-255-910. E-mail: moheeb982005@yahoo.co.uk
}

Received: October 24, 2013

Accepted: December 12, 2013

Online Published: February 21, 2014

doi:10.5539/ijbm.v9n3p122

URL: http://dx.doi.org/10.5539/ijbm.v9n3p122

\begin{abstract}
This study aims at exploring important details concerning traffic accidents in Jordan by studying the related financial costs (million JD) for the period (1995-2010). Twelve regression models have been treated. This study specifies the appropriate model which depends on the least of mean square error (MSE). We argue, based on our analysis, that compound function is the best way Business Process Management Concepts languages Architectures or studying the financial costs for traffic accidents in Jordan. All computations used in this paper performed using the Statistical Package for Social Sciences (SPSS) and (Minitab 14). The main results, based on the conducted analysis, are presented below:
\end{abstract}

- The study proved that the compound function is an appropriate and suitable model to measure and analyze the financial costs for the traffic accidents in Jordan which depends on the least of mean square error (MSE);

- The study proved that the response variable (time) has a significance effect on the dependent variable (financial costs for the traffic accidents);

- The study showed that the total financial cost for the traffic accidents is equal to 3025 million JD.;

The following are the main findings regarding traffic accidents in Jordan:

- Traffic accident is costly in Jordan.

- It is appropriate to utilize the compound function model to forecast the financial costs for the traffic accidents in Jordan, to draw plans for the future.

- Establishment of the traffic accident awareness will decrease the traffic accident.

- Governmental regulations can help in solving the traffic accidents problem.

- Maintaining the infrastructural road and providing people for all facilities will be helpful to solve the traffic accidents problem.

Keywords: appropriate model, compound function model, financial costs, Jordan, mse, time indicator, traffic accidents

\section{Introduction}

Jordan is located in the Middle East and situated between latitudes 29 and 33 north and longitudes 34 and 39 east, with an area of 89.3 thousand sq. $\mathrm{km}$. of which $7.8 \%$ is agricultural land (Central Bank of Jordan, 2007) and estimated of population at 6.113 million inhabitants in 2010 (Statistical Yearbook (2010). In Jordan, traffic accidents constitute a major problem. They are considered the second leading cause of death (AL-Masaeid, 2009), the number of accidents has increased from (122793) in 2009 to (140014) in 2010 by (14.02\%, fatalities have decreased from (676) in 2009 to (670) in 2010 by (0.89\%), injuries have increased from (15662) in 2009 to (17403) in 2010 by (11.12 \%). the cost of traffic accidents for 2010 is (311) million JDs, fatalities per 10,000 vehicles are (6.2) and the injuries per 10,000 vehicles are (161.8) as a result of traffic accidents, Fatalities per 100,000 Inhabitants are (11.0) and the injuries per 100,000 Inhabitants are (284.7) as a result of traffic accidents. Pedestrian accidents recorded (2.9\%) from the total number of accidents resulted in $(32.5 \%)$ from the total number of fatalities and (23.8\%) from the total number of injuries. Moreover, Crash accidents recorded (\%) 
from the total number of accidents resulted in $(45.4 \%)$ from the total number of fatalities and $(64.8 \%)$ from the total number of injuries. Injury accidents recorded (7.86\%), where property-damage accidents recorded (92.14\%) from the total number of accidents, the highest percentage of deaths within the age group (24-26) years and by $(9.4 \%)$ of all deaths overall, and the wounded was formed within the age group (21-23) years by $(10.26 \%)$ of the total wounded. The highest percentage of drivers involved in traffic accidents compared with the registered number are from the age group (21-23) years and older accounting for a rate $(22.48 \%)$ of all drivers involved in traffic accidents. The fatalities passengers percentage (34.92\%) and injuries $(40.45 \%)$ of the total fatalities and injuries. overall, most fatalities in traffic accidents were a result of using incorrect lane with percentage equal to (35.16\%) of the total traffic accidents errors (Statistical Yearbook (2004, 2007and 2010), Traffic Accidents in Jordan).

Table 1. The road traffic accidents time indicator $(2009,2010)$

\begin{tabular}{ll}
\hline \multicolumn{1}{c}{ Road Traffic Accidents Time Indicator 2010 } & Road Traffic Accidents Time Indicator 2009 \\
Every 24 hours, 11 pedistrian accidents occure. & Every 24 hours, 11 pedestrian accidents occur. \\
$\begin{array}{l}\text { Approximately every } 13 \text { hours, a person is killed in a traffic } \\
\text { accident. }\end{array}$ & $\begin{array}{l}\text { Approximately every } 13 \text { hours, a person is killed in a traffic accident. } \\
\text { Approximately every } 30 \text { minutes, a person is injured in a } \\
\text { traffic accident. }\end{array}$ \\
\hline
\end{tabular}

Source: Statistical Yearbook (2004, 2007and 2010), Traffic Accidents in Jordan, Public Security Directorate.

Table 1 shows no high differences between the road traffic accidents time indicator 2010 and the road traffic accidents time indicator 2009 .

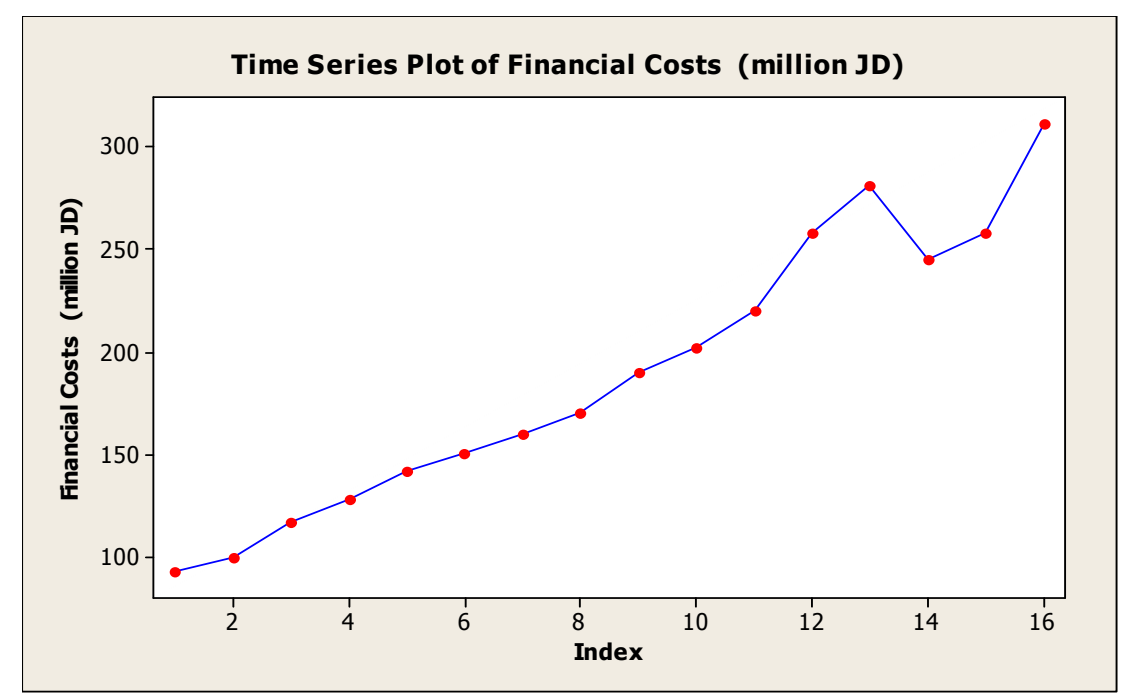

Figure 1. Financial costs for the traffic accidents (million JD) in Jordan for period (1995-2010)

Study Concepts (Statistical Yearbook 2010, Traffic Accidents): This study includes the following concepts (Statistical Yearbook (2004, 2007, and 2010), Traffic Accidents in Jordan).

Traffic Accident: Any incident caused by at least one vehicle resulted in injuries or fatalities or Property damages only.

Fatal Injury (Fatality): Is the infection that usually leads to death, either directly or because of complications during one month of the incidence.

Slight Injury: Any injury resulting from a traffic accident, including superficial wounds and bruises, as well as entries to the hospital for a period not exceeding ( 24 hours) definition does not include scratches and bruises and 
enter the hospital for Surveillance.

Serious Injury: Is the infections that need to be interventions specialized medical, within hospitals or outside, such as surgery or treating bone fractures, or deal with cases that nerves and other includes cases of head injuries and loss of consciousness according to (Glasgow coma scale): (0-15) infection is severe if the measurement at least 10 .

\section{Previous Studies}

There are many notable studies on the subject. Ghee et al. (1997) undertook a study on the analysis of existing data on socio-economic impacts of road traffic accidents in developing countries. The research considered the extent of the impact of road traffic injuries and deaths on these countries from social and economic standpoints. The main objective of the research was to widen the understanding of the consequence of road accidents on the economy and to measure their repercussion in socio-economic terms. The study indicated that the World Bank and the World Health Organization separately estimated that there were about half a million fatalities and 15 million people that were hurt each year due to highway traffic related incidents. According to the study also, approximately 60 percent of those that died and those that were injured came from the low and middle income peoples of the world. Figures from other related studies were used to determine that there was about 25 percent under-reporting of road crash related deaths in developing countries. Comparatively, the extent of under-reporting of road accident deaths in developed countries was only about six percent.

J. Teran-Santos et al. (1999) the National Commission on Sleep Disorders Research in the United States estimated the overall cost of accidents related to drowsiness in 1988 as $\$ 43$ billion to $\$ 56$ billion. The commission found that drowsiness may be involved in 36 percent of all fatal traffic accidents and in 42 to 54 percent of all accidents.

The research by Nantulya and Reich (2002) was centered on road traffic injuries in developing countries as the neglected epidemic. The research portrayed road crash injuries as a leading cause of fatalities and disabilities all over the world more especially in developing parts of the world. The study pointed out that highway crash injuries are now in the ninth place in the world as the most cause of serious injuries and is likely to rise to the third position in the 60 year 2020. Those who usually get involved in injuries related to traffic crashes are mainly those between the ages of 15 to 44 years because they have to work to support themselves and/or their families.

Ehikhamenor and Obianwu (2002) suggested that setting maximum allowable blood alcohol concentration levels as a means for enforcing and preventing drunkenness while operating motorized automobiles would serve as a means of control to keep people out of the highways before the innocent population gets unnecessarily hurt. They explained that most developed countries already had in place a very strict enforcement of the legislation pertaining to blood alcohol concentration and have 40 established thresholds for what constitutes driving while drunk.

Davis et al. (2003) conducted a research on how to improve road safety through the reduction of driving while impaired in developing countries. The intention of the research was to evaluate all the information that was already known about people operating automobile while impaired by alcohol, drugs, or fatigue primarily in developing countries. This research entailed gathering information with regard to the existing problem, using available literature to put in perspective the ramifications of the impairment problem from road safety standpoint, and ultimately, to find out ways to inform and educate the mass in developing countries so as to ameliorate the problem. Countries in Africa, South East Asia, and Latin America and Caribbean countries were studied. The reviews showed that these countries were collectively experiencing increasing deterioration in safety related road practices leading to large numbers of road crashes and eventual casualties. Impairment by alcohol was the most conspicuous compared to fatigue and other drugs because of its availability and use in social lifestyle. Most governments in developing countries do not regard road safety issues as very important. For this reason, those governments do not have transportation safety high on their priority lists. Consequently, they do not find it worthy enough to have committed to it adequate resources that would promote and ensure the proper execution of public protection policies.

Bener et al. (2003) was intended to review the approach that could bring about the safety of the road users in developing world. Their research credited the availability of crude oil in the Gulf region as the main catalyst as to why there was a rise in population in the surrounding areas of the region; hence a rise in automobile possession as well as an increase in road construction ventures. Vehicle ownership in the majority of African countries is not as high as in many other countries more especially those in industrial nations. 
In a study that was conducted by Odero (2004), he pointed out that in excess of one million people die on highway traffic crashes and well over 50 million more sustain one type of injury or another annually all over the world. According to his research, highway crash injuries were echoed to be the 9th in the world as a principal reason for injury related disability. This standing was anticipated to climb up to 3rd as primary cause of disability due to highway crashes by the year 2020. The majority of all the deaths and injuries on the world's highway network occur primarily in developing countries where well over 6185 percent and 95 percent of yearly highway traffic crashes and disabilities from crash injuries, respectively occur. The yearly financial toll of these crashes on the world at large is estimated to be more than $\$ 500$ billion, $\$ 65$ billion of which is in the developing countries.

Vasconcellos (2005) study on traffic accident risks in developing countries: superseding biased approaches showed that traffic accidents stand as one of the 49 most important health problems in industrialized and developing countries alike due to varying causes and conditions. The study pointed to the collision between automobile and an object or another automobile, moving or stationary, as the distinct universal characteristic of most traffic accidents at all times. The incidences of traffic accident problems started to increase in the early parts of the century in developed countries following the quick increase in the number of motorized automobiles. The developing countries, on the other hand, started to experience a spike in traffic crashes in the 1970s when they started making more use of motorized vehicles for transportation of goods and people.

Sittipan Sittikariya (2006) dissertation addresses the impact of critical modeling issues on the statistical significance of specifications correlated with traffic accident frequencies. Also, this research intended to shed new light on the major factors contributing to the occurrence of median crossover accidents, which are particularly severe. Furthermore, the research aimed to lay out methodologies that provide significant improvements in frequency predictions. The entire highway network of Washington State is used as the empirical setting. The database was developed over several years of observations and includes median crossover accident data, geometric and traffic volume information as well as weather data. The major contribution of this dissertation is the development of modeling taxonomies where assumptions under frequentist and Bayesian methods are incorporated through examination of model equivalencies.

Al-Masaeid (2009) paper investigated the characteristics of traffic accidents in Jordan and evaluated the safety impact of policy measures undertaken in 2008, including intensification of police enforcement and implementation of traffic law with stiff penalty levels. To accomplish these objectives, accidents' data of 1998 through 2007 were obtained from Jordan Traffic Institute and other related sources Finally, it is recommended to restructure and empower the Higher Council for Traffic Safety to be able to draw a comprehensive strategy with clear vision and rational safety policies to tackle the traffic accidents' problem.

Simon et al. (2011) argued that engineering and improved road safety education has resulted in an overall decrease in road traffic accident numbers in Christchurch, New Zealand. The temporal trends of crash data from 1980 to 2004 reveal that lowering of crash rates is not occurring at a uniform rate throughout the day, with comparative increases in crash rates occurring during morning rush hour, and during the 'school run'. No spatial clustering around schools was identified. This suggests that policies to reduce school travel related road accidents need to be focused on reducing overall traffic levels rather than focusing geographically on areas in the immediate vicinity of schools.

\section{Analysis Procedures}

To achieve the objectives of the study, we used the Statistical Package for Social Sciences (SPSS) and (Minitab 14).

\subsection{Methodlogy}

In this paper, we used (12) regression models, Linear Function, Quadratic Function, Cubic Function, Half -Logarithmic Function, Double-Logarithmic Function, Inverse Function, Inverse - Logarithmic Function, Ratio -Half Logarithmic Function, Square Root Function, Compound Function, Power Function, and Growth Function, depending on the data issued by the Statistical Yearbook (2004, 2009 and 2010), Traffic Accidents in Jordan, we have also tested all these models and selected the most appropriate model which depends on the least of mean square error (MSE) .

\subsection{Models}

We used the following models (Greene, 1993):

1) Linear Function: $y i=b o+b l t i+U i$ 
2) Quadratic Function: $y i=b o+b 1 t i+b 2 t i * * 2+U i$

3) Cubic Function: $y i=b o+b 1 t i+b 2 t i * * 2+b 3 t i * * 3+U i$

4) Half-Logarithmic Function: $y i=b o+b 1 L n(t i)+U i$

5) Double -Logarithmic Function: Ln (yi) bo $+b 1 L n(t i)+U i$

6) Inverse Function: $y i=b o-t i+U i$

7) Inverse - Logarithmic Function: $L n(y i)=b o-t i+U i$

8) Ratio -Half Logarithmic Function: ti $=$ bo-b1Ln (ti) $+\mathrm{Ui}$

9) Square Root Function: $y i=$ bo + b1 $\sqrt{t i}+\mathrm{Ui}$

10) Compound Function: $\operatorname{Ln}(y i)=\operatorname{Ln}(b o)+t i \operatorname{Ln}(b 1)+U i$

11) Power Function: $\operatorname{Ln}(y i)=\operatorname{Ln}(b o)+b 1 \operatorname{Ln}(t i)+\operatorname{Ln}(U i)$

12) Growth Function: $\operatorname{Ln}(y i)=b o+b l t i+U i$

Where:

$y i$ : is the dependent variable (Financial costs for the traffic accidents (million JD).

ti: is the independent variable (Time).

$\mathrm{Ln}$ : is the natural logarithmic.

$\mathrm{Ui}$ : is a random disturbance.

$\mathrm{Ui} \sim \mathrm{N}\left(0, \sigma^{2} u\right)$.

DATA: We utilized the data issued by the Statistical Yearbook (2004, 2009 and 2010), Traffic Accidents in Jordan.

Table 2. The financial costs (million JD) for the traffic accidents in Jordan (1995-2010)

\begin{tabular}{lc}
\hline Year & Financial Costs (million JD) \\
\hline 1995 & 93 \\
1996 & 100 \\
1997 & 117 \\
1998 & 128 \\
1999 & 142 \\
2000 & 150 \\
2001 & 160 \\
2002 & 170 \\
2003 & 190 \\
2004 & 202 \\
2005 & 220 \\
2006 & 258 \\
2007 & 281 \\
2008 & 245 \\
2009 & 258 \\
2010 & 311 \\
\hline
\end{tabular}

Source: Statistical Yearbook (2010), Traffic Accidents in Jordan.

Table 2 shows that the financial costs for the traffic accidents are increasing from year to another, and we noticed that the total financial costs for period (1995-2010) are 3025 million JD. 
Table 3. Summary of results, estimated models, standard error, calculated t, sig for each estimator and R square, calculated f, finally the mean square error (mse) for every model

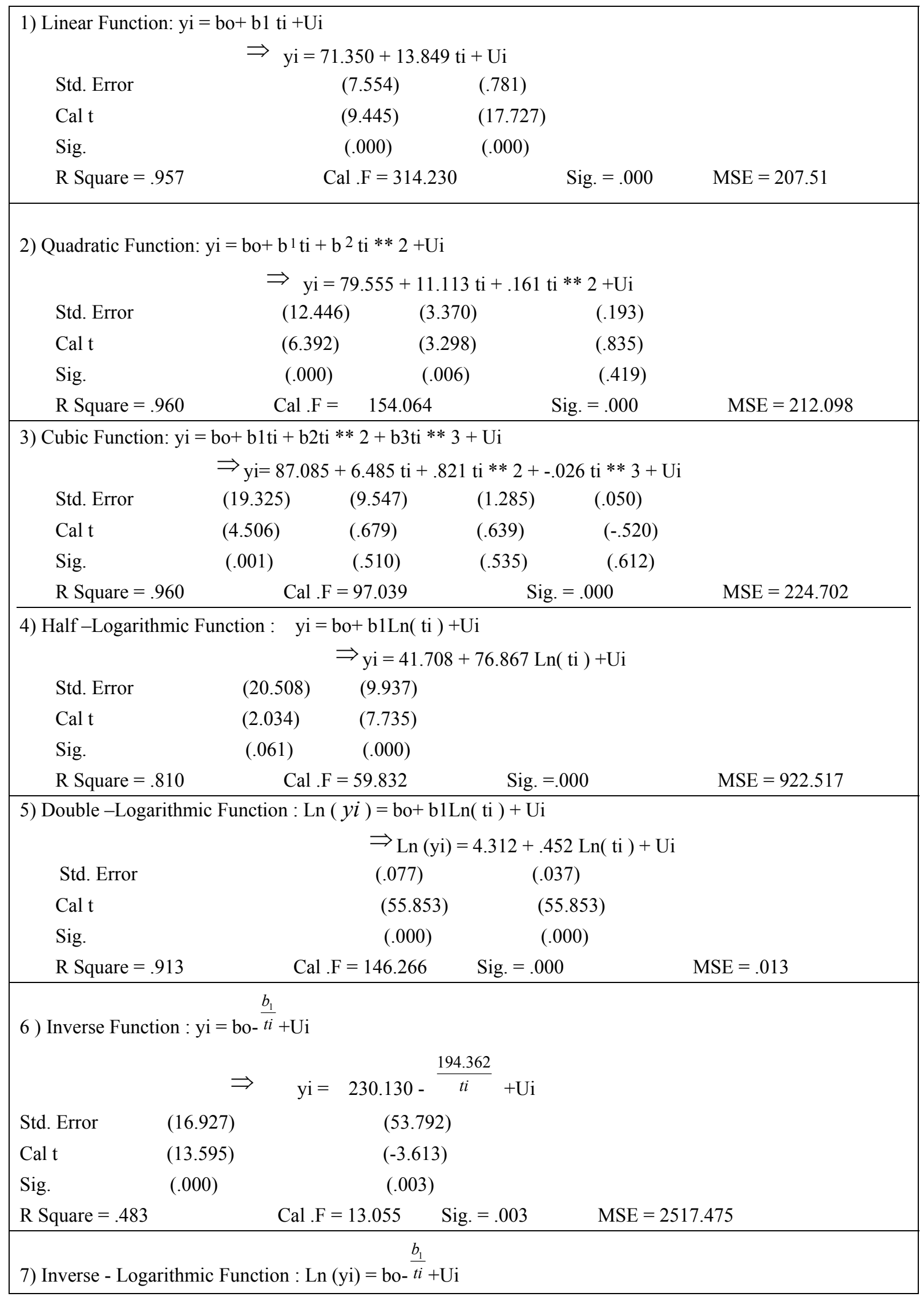




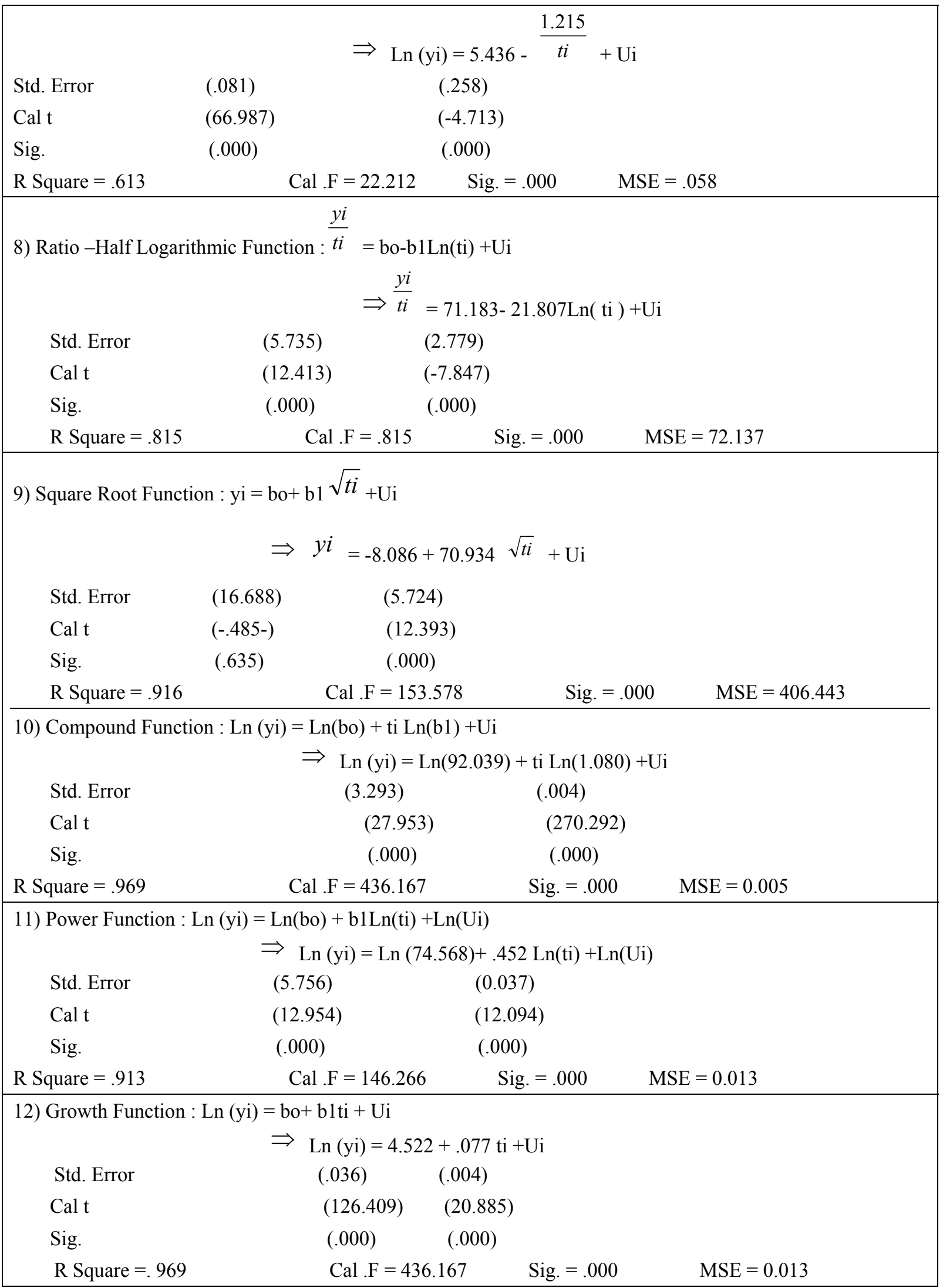

Table 3 shows that the best model depending on the least of mean square error (MSE) is the compound model. This model has (0.005) mean square model, and the response variable (time) has a significance effect on the 
dependent variable (financial costs for the traffic accidents), and the coefficient of determination (R Square) equal (.969) .This means that the explanatory variable explained the percent $(96.9 \%)$ of the changes in the response variable.

\section{Results}

Based on the analysis made, the following are the main results:

- The study proved that the compound function is the most appropriate and suitable model to measure and analyze the financial costs for the traffic accidents in Jordan which depends on the least of mean square error (MSE).

- The study proved that the response variable (time) has a significance effect on the dependent variable (financial costs for the traffic accidents).

- The study showed that the total financial costs for the traffic accidents are equal to 3025 million JD, which means the average of financial costs for the traffic accidents 189.06 million JD yearly.

\section{Recommendations}

The study findings regarding traffic accidents in Jordan are as the following:

- It is appropriate to adopt the compound function model to forecast the financial costs for the traffic accidents in Jordan, to draw plans for the future.

- Establishment of the traffic accident awareness will decree the traffic accident.

- Governmental regulations will be helpful to solve the traffic accidents problem.

- Maintaining the infrastructural road and providing people for all facilities will be helpful to solve the traffic accidents problem.

\section{References}

Bener, A., Fikri, M., Abu-Zidan, A. K., Bensiali, A., Al-Mulla, A., \& Khair, S. J. (2003). Strategy to Improve Road Safety in Developing Countries. Saudi Medical Journal, 24(6), 603-608.

Davis, A., Quimby, A., Odero, W., Gururaj, G., \& Hijar, M. (2003). Improving Road Safety by Reducing Impaired Driving in Developing Countries: A Scoping Study. Transport Research Foundation Group of Companies.

Ehikhamenor, E. E., \& Obianwu, H. O. (2002). Global Legislation on Blood Alcohol Central Bank of Jordan. Monthly Statistical Bulletin, 43(3), 103.

Ghee, C., Silcock, D., Astrop, A., \& Jacobs, G. (1997). Socio-Economic 166 Aspects of Road Accidents in Developing Countries. Transport Research Laboratory.

Hashem, R. A. (2009). Traffic Accidents in Jordan. Jordan Journal of Civil Engineering, 3(4), 331-343.

Nantulya, V. M., \& Reich, M. R. (2002). The Neglected epidemic: Road traffic Injuries in Developing Countries.

Odero, W. (2004). Road Traffic Injury Research in Africa: Context and Priorities. A Presentation at the Global Forum for Health research Conference (Forum 8), Mexico City.

Simon, K. H., Clive, E., \& Phil, B. (2011). The impact of the 'school run' on road traffic accidents: A spatio-temporal analysis. Journal of Transport Geography, 19(4), 467-1006.

Sittipan, S. (2006). Methodological Approaches to Incorporate Heterogeneity in Traffic Accidents Frequency Models. A Thesis in civil Engineering, December 2006. The Pennsylvania State University.

Statistical Year Book. (2004, 2007, 2010). Traffic Accidents in Jordan, Public Security Directorate. Amman, Jordan.

Statistical Year Book. (2010). Department of Statistics. Amman, Jordan.

Teran-Santos, J., \& Jimenez-Gomez, A. (1999). Cordero-Guevara. The New England Journal of Medicine, $340(11)$.

Vasconcellos, E. A. (2005). Traffic Accident Risks in Developing Countries: Supersedin Biased Approaches. paper presented to the 16th International Cooperation on Theories and Concepts in Traffic Safety (ICTCT) Workshop, Netherlands.

William, H. G. (1993). Econometric Analysis (2nd ed.). Macmillan Publishing Company. 


\section{Copyrights}

Copyright for this article is retained by the author(s), with first publication rights granted to the journal.

This is an open-access article distributed under the terms and conditions of the Creative Commons Attribution license (http://creativecommons.org/licenses/by/3.0/). 